Proceedings of the 2005 Winter Simulation Conference

M. E. Kuhl, N. M. Steiger, F. B. Armstrong, and J. A. Joines, eds.

\title{
A DISCRETE EVENT SIMULATION MODEL FOR ASSEMBLING THE INTERNATIONAL SPACE STATION
}

\author{
Grant R. Cates \\ Operations Integration Division \\ Shuttle Processing Directorate \\ Kennedy Space Center, FL 32899, U.S.A.
}

\author{
Mansooreh Mollaghasemi \\ Industrial Engineering \& Management Systems \\ 4000 Central Florida Blvd. \\ University of Central Florida \\ Orlando, FL 32816, U.S.A.
}

\begin{abstract}
In late 2002 and early 2003, a discrete event simulation (DES) model was used to help NASA assess the viability of achieving a politically important goal. The goal was to complete the assembly of the International Space Station through the milestone known as United States Core Complete by February $19^{\text {th }}, 2004$. The analysis provided by the DES model was subsequently shown to be consistent with NASA's official assessments regarding the completion date for U.S. Core Complete. The success of this DES model has led to further improvements in modeling NASA's project to assemble the International Space Station.
\end{abstract}

\section{INTRODUCTION}

Since 1984, NASA has been engaged in a massive project to create the largest and most complex orbiting Space Station ever built. This project includes international partners from Russia, Europe, and Japan. The project fell behind schedule and went over budget. In 2001 the project was "on probation" and NASA was pressured to prove that future schedules and budgets could be met or risk losing support from the White House and Congress (Gehman 2003). Consequently, a goal was established to complete the United States core portion of the Space Station by February 19, 2004. It was imperative that this milestone a.k.a. "U.S. Core Complete" be met.

By late 2002, the plan to achieve the goal was in jeopardy. In December, NASA initiated an assessment to determine how much margin, a.k.a. safety time or slack, was in the processing schedules for each of the seven Space Shuttle missions required to achieve the U.S. Core Complete milestone. To get from December of 2002, to "U.S. Core Complete" by February 19, 2004, would require seven successful Space Shuttle missions-STS-114, 115, $116,117,118,119$, and 120 . The seven missions needed to occur in that precise order. U.S. Core Complete was synonymous with delivery of the Node- 2 component to the In- ternational Space Station. STS-120 was slated to fly the Node- 2 mission. In regard to the order of the missions, the project was similar to the construction of a multiple story building, with the second story needing the first story to be structurally complete and so on.

The order of the Space Station assembly missions, including the Space Shuttle orbiters that would fly the respective missions, is shown in Figure 1.

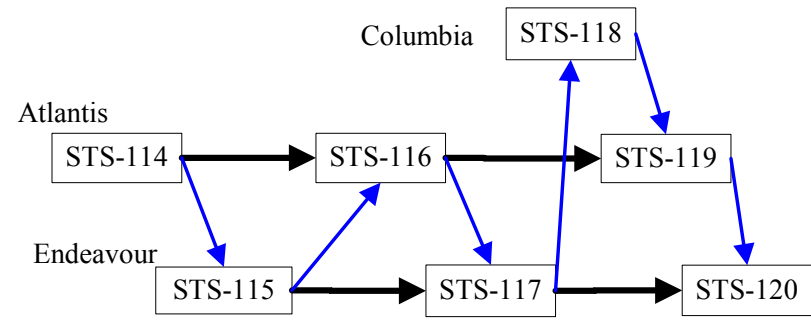

Figure 1: Assembly Sequence

\section{SHUTTLE MISSION FLOW}

The Space Shuttle Orbiters undergo the same processing flow for each mission. Figure 2 shows a simplified diagram of the orbiter processing and mission cycle for a typical Space Shuttle mission. A more complete Shuttle flow has been previously described and modeled (Cates et al. 2002).

The first step in the mission flow is called orbiter processing and occurs in the Orbiter Processing Facility (OPF). The orbiter is de-configured from the previous mission, undergoes detailed inspections and testing, and finally is configured for the upcoming mission. The process takes approximately 13 weeks. There is, however, variability in that number. Planned work is scheduled Monday through Friday, typically on a 2-shift per day basis. Three quarters of the Saturdays have planned work and one quarter of the Sundays have scheduled work. The remainders are available as margin. 


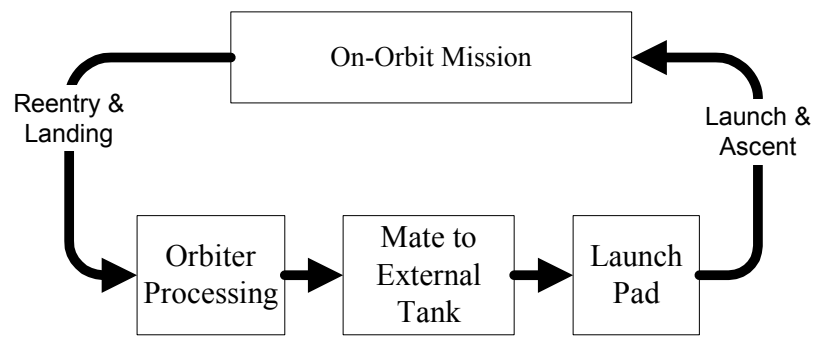

Figure 2: Shuttle Processing Flow

Given a 13 week processing flow, then two Saturdays and five Sundays might typically be available as margin. These numbers will vary based upon the specifics of the processing flow for each mission. The Saturday and Sunday margin days are used as required to accommodate work content growth that occurs during the processing flow. Holiday margin may also be available if the processing flow extends over a time period containing a holiday such as Thanksgiving, Fourth of July, Christmas to New Years, etc. Holidays are typically protected as much as possible and used only as a last resort.

A category of margin unique to Orbiter processing is called Dryden Reserve and it stems from the potential that the orbiter may land in California. There is approximately a 20 percent chance that an orbiter will be diverted to the Dryden Flight Research Center in California. When this happens it takes several days to prepare and ferry the orbiter back to Florida. The start of the Orbiter processing flow is delayed by that amount. Consequently, NASA holds six days of Dryden Reserve for each Orbiter processing flow as schedule insurance.

Once the orbiter has completed processing in the OPF, the orbiter then goes to the Vehicle Assembly Building (VAB) where it is mated to the External Tank. The Tank has previously been placed between the Solid Rocket Boosters. This activity typically occurs over seven calendar days. Five of these days have planned work and two are available as margin.

Finally the orbiter, which is now a part of what is called an Integrated Space Shuttle Vehicle, goes to the launch pad where it is prepared for launch. Launch preparations at the launch pad typically take about three weeks with six weekend days usually available as margin. There may also be a couple in-week contingency days depending upon the specific mission.

The OPF, VAB, and Pad pre-launch activities are the only places where schedule margin resides. However, there are other activities in the operations cycle of the orbiter and they are described below. These activities are important to understand because, while they have little schedule margin - on the order of a few hours - they are significant contributors to schedule risk.

After the launch countdown preparations have been completed, the three-day launch countdown is conducted.
There is approximately a 55 percent chance of launching. Approximately 45 percent of the time launch does not occur. The duration of the time required to get back to a subsequent launch attempt is highly dependent upon the reason for the delay. For weather related delays, it typically takes one day. More difficult technical problems may take several weeks to correct before launch can be attempted again. Because delays experienced during launch countdown occur after all the margin for that mission has been used, the main effect of these delays is to hinder the start of the subsequent OPF processing flow.

Once launch does occur the orbiter enters earth orbit to perform its assigned mission. Mission duration is typically planned for 10 to 11 days. However, the duration of the mission can grow. For example, on occasion the mission is extended by one day so as to achieve all of the mission objectives. More often missions are extended in order to wait for the landing weather to improve in Florida. Due to commodity limitations, the total on-orbit time cannot extend beyond approximately four days. The effect of mission duration growth is to delay the start of the next OPF flow.

This Space Shuttle flow model and the margin assessment effort was focused on the most critical resource: the Space Shuttle orbiter. While there are other important resources such as the Solid Rocket Boosters and External Tank, the experience has been that the orbiter tends to be the critical path resource. The standalone processing flows for the Solid Rocket Boosters and External Tank are planned such that they have sufficient schedule margin to preclude, with reasonable confidence, their becoming the critical path.

\section{MARGIN ASSESSMENT RESULTS}

The information assembled for the margin assessment is shown in Table 1. The table shows the seven Space Station assembly missions and schedule margin, which is divided into three categories - processing, holidays, and Dryden Reserve.

Table 1: Margin in Assembly Sequence

\begin{tabular}{ccccc}
$\begin{array}{c}\text { STS } \\
\text { Mission }\end{array}$ & $\begin{array}{c}\text { Processing } \\
\text { Margin }\end{array}$ & Holidays & $\begin{array}{c}\text { Dryden } \\
\text { Reserve }\end{array}$ & Totals \\
\hline 114 & 6 & 0 & 0 & 6 \\
115 & 17 & 1 & 0 & 18 \\
116 & 26 & 3 & 6 & 35 \\
117 & 18 & 2 & 6 & 26 \\
118 & 42 & 2 & 6 & 50 \\
119 & 14 & 12 & 6 & 32 \\
120 & 17 & 11 & 6 & 34 \\
\cline { 2 - 5 } & 140 & 31 & 30 & 201
\end{tabular}


Figure 3 shows the assembly sequence with margin for each mission as well as the margin between each mission. The thick horizontal bars represent the Orbiter Processing, VAB, and Pad activities up to start of launch countdown. The numbers within these bars are the amount of available margin days. The thin diagonal bars represent the sequencing constraints of the Space Shuttle mission. The numbers within these diagonal bars are the number of days that the launch of the preceding mission can slip without impacting the next launch. The rectangular boxes represent the time period of launch countdown, on-orbit mission, and landing. These periods contain no significant margin.

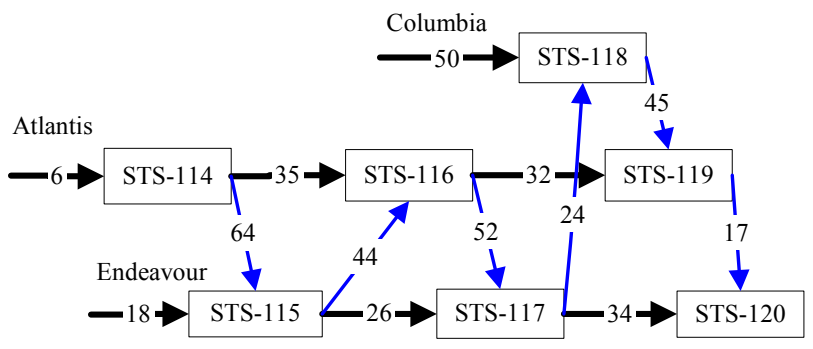

Figure 3: Assembly Sequence with Margin

NASA officials questioned whether or not launch of STS-120 (Node-2) on February 19, 2004 was likely given the amount of margin shown in Table 1 and Figure 3. In order to begin to answer that question it was clearly important to understand how often margin days were used in the past.

\section{USE OF MARGIN IN THE PAST}

Historical data, which fortunately was available, was collected to build chronological run charts of added work days after Space Shuttle mission processing flows are base-lined at the Delta Launch Site Flow Review. This review is analogous to a formal project review in which project task durations are agreed to. The run charts were analyzed to identify trends and outliers before determining what subset of the total historical data should be used as being predictive of future performance. Histograms and cumulative frequency distributions for added work days were then built for each of the project activities; i.e., Orbiter Processing, Mate to External Tank, and Launch Pad flows. As an example, Figure 4 shows the corresponding histogram and cumulative frequency distribution for the Orbiter Processing flow.

The information in Figure 4 indicates that having the ability to absorb four added work days would preserve the ability to complete Orbiter Processing on time with a .5 probability. To increase that probability to .9 would require the ability to absorb approximately 18 added work days.

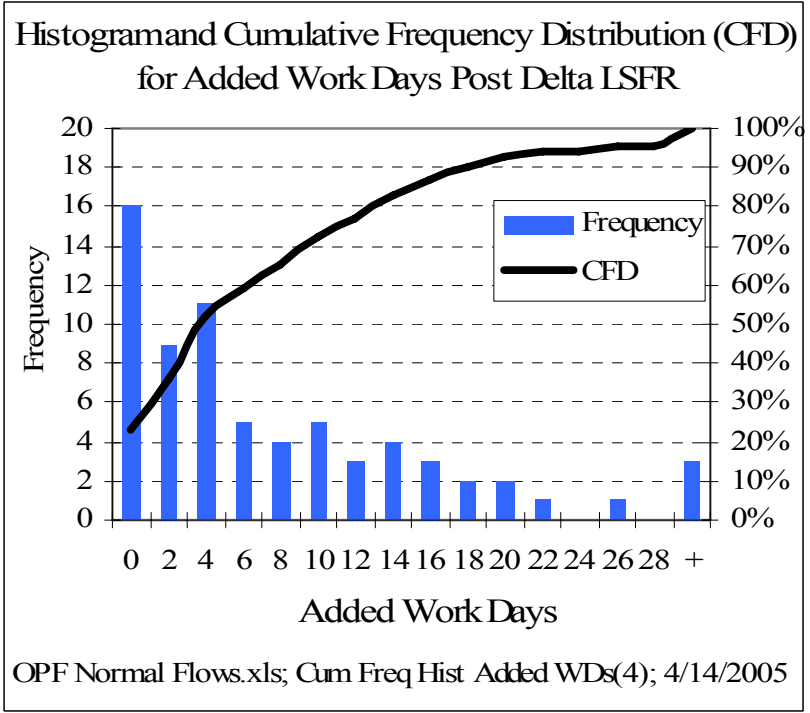

Figure 4: Orbiter Processing Historical Data

This same process was followed to analyze the VAB and Pad flows. Additionally, the historical data for added days occurring during Launch Countdown and the OnOrbit mission, as well as the added days as a result of DFRC landing was also reviewed. From this historicalbased review, one can determine how much margin would be required for a future Space Shuttle mission processing flow. However, this determination is limited by the fact that it applies to only one Space Shuttle mission and assumes that the project start date-designated as Orbiter Processing start - occurs on time. Additionally, the amount of margin required is a function of the level of confidence you want to have in achieving an on-time start to the next project. Table 2 shows the combined results.

Table 2: Margin to Ensure Next Project Starts on Time

\begin{tabular}{cccccccc} 
Confidence & OPF & VAB & Pad & Launch & Mission & Landing & Total \\
\hline $30 \%$ & 1 & 0 & 1 & 0 & 0 & 0 & 2 \\
$40 \%$ & 2 & 0 & 2 & 0 & 0 & 0 & 4 \\
$50 \%$ & 4 & 0 & 3 & 0 & 0 & 0 & 7 \\
$60 \%$ & 5 & 1 & 4 & 1 & 0 & 0 & 11 \\
$70 \%$ & 10 & 2 & 6 & 2 & 0 & 0 & 20 \\
$80 \%$ & 14 & 3 & 9 & 5 & 1 & 12 & 44 \\
$90 \%$ & 18 & 4 & 14 & 14 & 1 & 13 & 64 \\
$99 \%$ & 32 & 14 & 28 & 70 & 3 & 14 & 161
\end{tabular}

The above process did not yield a quantitative assessment of the range of likely launch dates for the STS-120 Node-2 mission. Consequently, it was decided to develop a discrete event simulation-based assessment. 


\section{DES MODEL OF ISS ASSEMBLY SEQUENCE}

Once it had been decided to employ discrete event simulation, the effort focused upon developing a model that would utilize the already available historical data analysis. The primary goal for the model was to provide a quantitative assessment of the likelihood of launching STS-120 (Node-2) on February 19, 2004, or subsequent dates.

Each of the three major Space Shuttle mission preparation operations - Orbiter Processing, VAB, and Pad - were modeled in the same way using the activity construct shown in Figure 5.

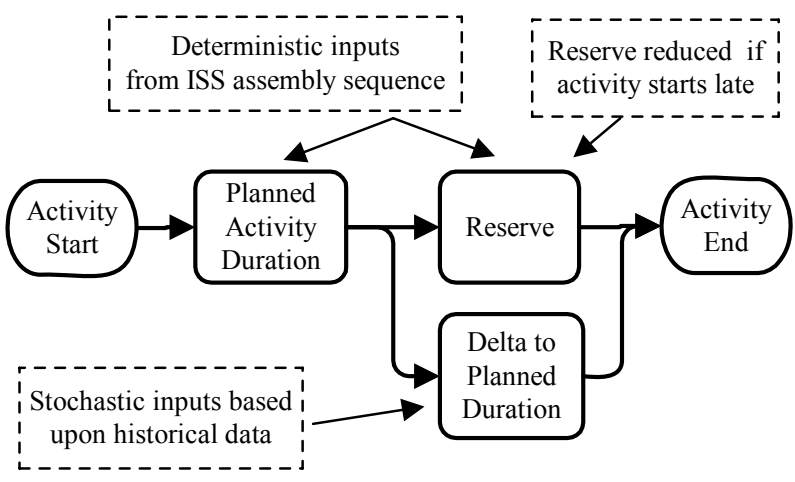

Figure 5: Activity Construct

Planned processing days along with available margin days for each of the three major mission preparation operations are inputs for the model. During runs of the simulation, arrival of the orbiter entity at each of the three locations is checked versus the planned arrival date and the amount of margin is adjusted accordingly. The margin days were modeled as processing margin, which included Dryden Reserve, and holiday margin. For modeling purposes Dryden Reserve was added to the processing margin since that reserve becomes available as margin should the orbiter land in Florida as planned. Holiday margin was modeled separately because it was initially assumed that holidays were not available to be worked unless directed by management. There is higher cost for working over holidays.

Empirical distributions for added days were developed from the analysis of the historical data. For example, the histogram and cumulative frequency distribution shown in Figure 4 was used to generate an empirical distribution for added days during an Orbiter Processing flow.

Launch of the shuttle was modeled using an event probability node containing probabilities for launching or being delayed and if so the delay type. The delay type determines the length of time required to return to the next launch attempt.

Likewise, the landing was modeled using an event probability node with paths for either landing at KSC or DFRC. A cyclical component was added to allow the space shuttle orbiter to stay on orbit for up to four days to wait for favorable weather at KSC. If it is favorable, then landing at $\mathrm{KSC}$ occurs.

The simulation model was tailored to specifically model the processing and sequencing of the seven missions. A predecessor mission on the orbiter Columbia that was not part of the seven missions was not included in the model. Additionally, the possibility of a serious anomaly such as a loss of vehicle event was discounted. Unfortunately, a loss of vehicle event did occur on the predecessor mission flown by Columbia. However, that accident occurred after the simulation model was built and after the analysis was presented to NASA officials.

The model was first run in a deterministic mode to ensure that it would properly reproduce launch of STS- 120 on the planned date. After this step was successfully achieved the model was populated with the stochastic elements.

\section{DES MODEL RESULTS}

The model was run in the stochastic mode initially for 300 , and later for 900, replications. Figure 6 shows a histogram of the 900 replications along with the cumulative percentage. The cumulative percentage line represents the completion distribution function (CDF) for the launch date of STS-120.

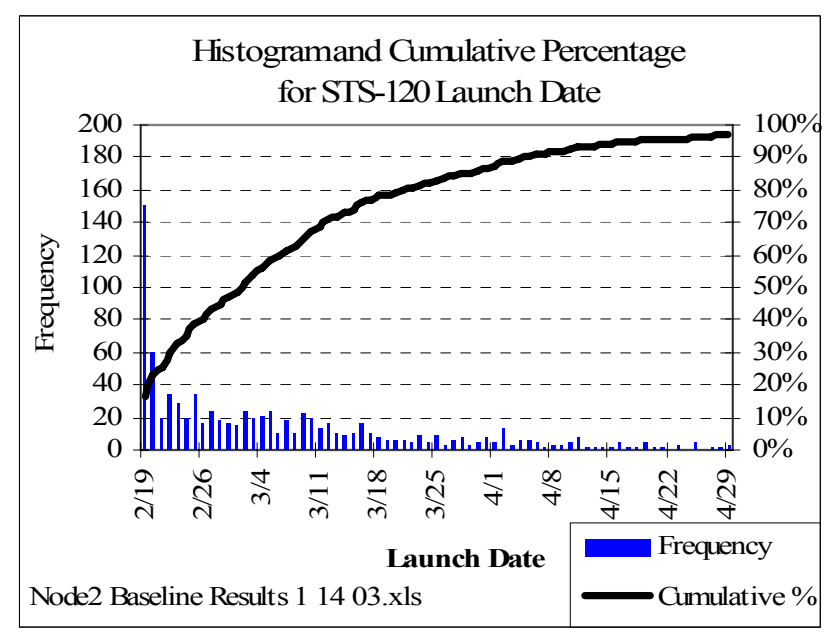

Figure 6: Simulation Results

Launch of STS-120 occurred on the planned dateFebruary 19, 2004 - in approximately 16 percent of the runs. Launch occurred within one week of the planned launch date approximately 40 percent of the time. The $50^{\text {th }}$ percent probability of launch occurred between March 1st and March 2 nd. The $80^{\text {th }}$ percentile occurred on March $21^{\text {st }}$ and the $90^{\text {th }}$ percentile occurred on April $4^{\text {th }}$. The 99 percentile is approximately June $17^{\text {th }}$. Note that the CDF in 
Figure 6 represents a middle value of a normally distributed range of possible values. Further simulation runs were subsequently performed to specify the confidence bands.

The margin analysis, DES model description, and results were presented to NASA officials on January 6, 2003. A second presentation to a wider audience of higher level NASA officials occurred the next day. The then present political imperative to achieve the February 19, 2004 launch date was well known. Thus, it was also known that a quantitative analysis indicating that this date was unlikely to be achieved might be unwelcome. Consequently, during the briefing on January $7^{\text {th }}$, emphasis was placed on explaining that the analysis included launch dates beyond February $19^{\text {th }}$ and showed over an 80 percent chance of launch occurring by the first of April.

\section{CONCLUSION}

The simulation assessment was subsequently found to be consistent with the official Space Shuttle Program positions on the issue of the STS-120 launch date. One of these positions was that February 19th was the planned launch date, but that there was up to a 45-day (plus or minus 15 days) threat to that date. A similar position expressed by NASA officials was that the most probable launch date for STS-120 would occur between March 19 and April 19 (Gehman 2003). This consistency lent validity to the DES results and indicated, therefore, that the goal of providing a quantitative measure had been successfully achieved.

The success of the DES model in analyzing the viability of the Node-2 February 19, 2004 launch date led to subsequent improved DES models for NASA in support of the Vision for Space announced by President George W. Bush in January of 2004. That vision calls for the International Space Station to be completed by 2010 . These models also resulted in the development of a more general methodology for improving project management (Cates 2004).

\section{APPENDIX: ACRONYMS}

DES Discrete Event Simulation

OPF Orbiter Processing Facility

NASA National Aeronautics and Space Administration

STS Space Transportation System

VAB Vehicle Assembly Building

\section{REFERENCES}

Cates, G.R, Mollaghasemi, M., Rabadi, G., and Steele, M.J. 2002. Modeling the space shuttle, In Proceedings of the 2002 Winter Simulation Conference, ed. E. Yücesan, C.-H. Chen, J. L. Snowdon, and J. M. Charnes, 754-762. Available via <www. informs-
C. . org/wsc02papers/097.pdf> [Accessed August 15, 2005].

Cates, G.R. 2004. Improving project management with simulation and completion distribution functions. Doctoral dissertation, Department of Industrial Engineering and Management Systems, University of Central Florida, Orlando, Florida. Available via <http: / / purl. fcla. edu/fcla/etd/CFE00 $00209>$ [Accessed April 10, 2005].

Gehman, Harold W. Jr., et al. 2003. Report of the Columbia accident investigation board, Vol. 1, August.

\section{AUTHOR BIOGRAPHIES}

GRANT R. CATES is a manager in the Operations Integration division of the Space Shuttle Operations Directorate at the Kennedy Space Center. He received his Ph.D. from the University of Central Florida in 2004. He is a member of IIE, INFORMS, and AIAA. His e-mail address is $<$ grant.r.cates@nasa.gov>.

MANSOOREH MOLLAGHASEMI is an associate professor in the Industrial Engineering \& Management Systems department at the University of Central Florida. . She received her Ph.D. from the University of Louisville in 1991. Her research and teaching interests include simulation modeling and analysis of complex systems, statistical aspects of simulation and simulation optimization, operations research, probability and statistics, neural networks, and multiple criteria decision making. Her email address is $<$ mollagha@mail.ucf.edu>. 